\title{
Inter-evaluator heterogeneity of clinical diagnosis for locally advanced esophageal squamous cell carcinoma
}

\author{
Yasuo Hamamoto ${ }^{1}$ Masanori Nojima $^{2} \cdot$ Yu Aoki $^{3} \cdot$ Takeshi Suzuki $^{3} \cdot$ Kenta Kawasaki $^{3} \cdot$ Kenro Hirata $^{3}$. \\ Yasutaka Sukawa $^{3} \cdot$ Akira Kasuga $^{3} \cdot$ Hirofumi Kawakubo $^{4} \cdot$ Hiroya Takeuchi $^{4} \cdot$ Koji Murakami $^{5}$. \\ Hiromasa Takaishi ${ }^{4} \cdot$ Takanori Kanai $^{3} \cdot$ Yuko Kitagawa $^{4}$
}

Received: 1 March 2017 / Accepted: 18 May 2017 / Published online: 23 May 2017

(c) The Author(s) 2017. This article is an open access publication

\begin{abstract}
Background Identifying clinical resectability of locally advanced esophageal squamous cell carcinoma (ESCC) is important, although inter-evaluator heterogeneity (IEH) could exist, especially in borderline resectable (BLR) cases. To investigate the extent of heterogeneity, we conducted clinical diagnostic imaging questionnaires.

Materials and methods Five cases with clinical T3 or T4 cases, which were treated with neo-adjuvant triplet chemotherapy followed by surgery, were selected as the model. These cases were divided into two groups: curative resected cases (\#1-\#3) and non-curative resected cases (\#4 and \#5). Only imaging slides were shown without any information about patient characteristics or clinical course. The evaluators consisted of surgeons (staff and non-staff), medical oncologists, and an imaging radiologist; a total of 25 medical staff answered the questionnaire. Two questions (1: clinical $\mathrm{T}$ stage before chemotherapy, 2: resectability after chemotherapy) were answered. Occupational differences were assessed by comparing the results to the imaging radiologist.
\end{abstract}

Yasuo Hamamoto

yashmmt1971@gmail.com

1 Keio Cancer Center, Keio University School of Medicine, 35 Shinanomachi, Shinjukuku, Tokyo, Japan

2 Center for Translational Research, The Institute of Medical Science Hospital, The University of Tokyo, Tokyo, Japan

3 Division of Gastroenterology and Hepatology, Department of Internal Medicine, Keio University School of Medicine, 35 Shinanomachi, Tokyo, Japan

4 Division of Surgery, Keio University School of Medicine, 35 Shinanomachi, Shinjukuku, Tokyo, Japan

5 Department of Radiology, Keio University School of Medicine, 35 Shinanomachi, Shinjukuku, Tokyo, Japan
Results IEH was observed for clinical diagnosis before chemotherapy in one case (clinical T4: 52\%, clinical T3: $48 \%)$. In the other cases, most evaluators diagnosed them as clinical T4, with 76-88\% agreement. IEH for clinical resectability after chemotherapy was relatively small. Occupational IEH was observed in both before and after chemotherapy.

Conclusion IEH in decisions about treating BLR cases in ESCC should be considered in clinical practice. Multi-disciplinary teams are essential to overcome this problem.

Keywords Heterogeneity - Esophageal cancer .

Resectability

\section{Introduction}

The prognosis of locally advanced esophageal squamous cell carcinoma (ESCC) is generally poor, especially when the cancer is unresectable [1]. Definitive chemoradiotherapy with more than $60 \mathrm{~Gy}$ irradiation is the standard of care for advanced cases [2-4]. Several other treatment options, including resection, exist in general Japanese practice [5], although surgical removal is controversial $[6,7]$. Neo-adjuvant chemoradiotherapy with 30-50 Gy with selected surgery if possible is classically preferred in some institutions [8-10], since the clinical decision as to whether it is resectable is difficult. Some unresectable cases convert resectable after completion of neo-adjuvant treatment; however, this strategy is not beneficial for non-curative cases. Patients with these finally unresectable cases also fail to complete the definitive radiation dose.

Recently, triplet chemotherapy with docetaxel, cisplatin (CDDP), and 5-fluorouracil (DCF) has been reported to produce a remarkable response for $\mathrm{T} 4$ disease [11-13]. 


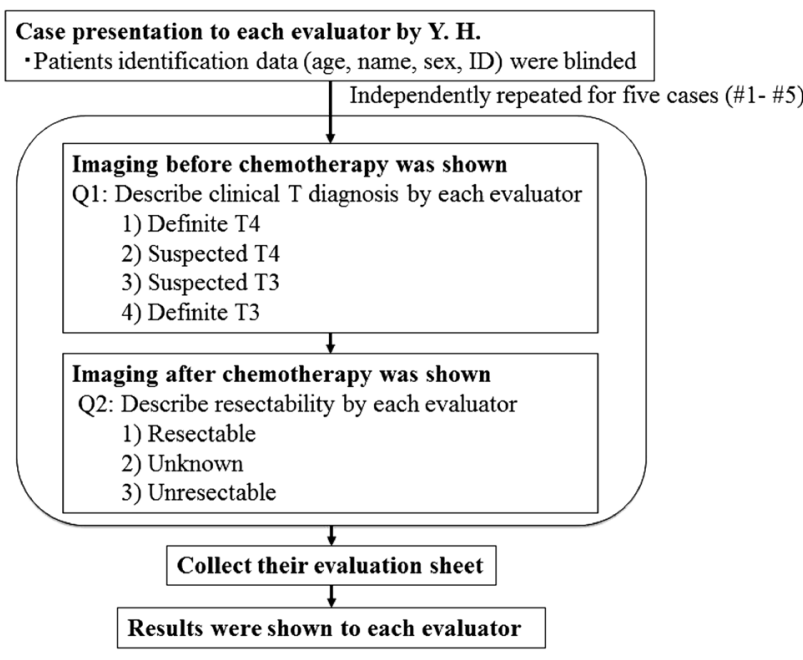

Fig. 1 Protocol schema of the study
The initial selection of intensive chemotherapy is beneficial when selecting the right patients for surgery. This strategy still has a curative option (salvage definitive chemoradiotherapy) if it fails to expedite curative surgery. However, this strategy also has several weaknesses. The most important problem with this strategy is consideration of borderline resectable (BLR) cases. As far as we know, there are no previous reports about a clear definition of BLR in ESCC.

Differential diagnoses for $\mathrm{T}$ stage are mainly judged using computed tomography (CT). The classical criteria for clinical T4 are considered the gold standard for advanced cases [14], although clinical diagnoses of marginal cases depend on the evaluator. Institutional heterogeneity may exist in these diagnoses, especially in BLR cases. Inter-evaluator heterogeneity (IEH) needs to be examined in more institutions with multiple specialized

Table 1 Cases of presentation: blinded information to evaluators

\begin{tabular}{|c|c|c|c|c|c|c|c|}
\hline Case & $\begin{array}{l}\text { c-stage (TNM } \\
\text { ver.7) }\end{array}$ & $\begin{array}{l}\text { Location (tho- } \\
\text { racic) }\end{array}$ & $\begin{array}{l}\text { Pre-operative } \\
\text { treatments }\end{array}$ & $\begin{array}{l}\text { Curative resec- } \\
\text { tion }\end{array}$ & P-stage & $\begin{array}{l}\text { Pathological } \\
\text { grade }\end{array}$ & Comments \\
\hline$\# 1$ & $\begin{array}{l}\text { c-stage IIA } \\
\text { cT3N0M0 }\end{array}$ & Lower & DCF 3 cycles & Yes & pT3N1M0 & Grade 1a & $\begin{array}{l}\text { T3 case, aorta } \\
\text { invasion need to } \\
\text { discuss } \\
\text { Adhesion area is } \\
\text { not as wide as T4 } \\
\text { Initially judged as } \\
\text { resectable }\end{array}$ \\
\hline \#2 & $\begin{array}{l}\text { c-stage III } \\
\text { cT4b(Br)N1M0 }\end{array}$ & Middle & DCF 3 cycles & Yes & pT3N1M0 & Grade 1a & $\begin{array}{l}\text { Typical BLR case } \\
\text { (relatively T4) } \\
\text { Deformity of } \\
\text { bronchus were } \\
\text { evident } \\
\text { Finally curative } \\
\text { resection }\end{array}$ \\
\hline \#3 & $\begin{array}{l}\text { c-stage IVa } \\
\text { cT4b(Br)N4M0 }\end{array}$ & Middle & DCF 3 cycles & Yes & pT3N0M0 & Grade $1 b$ & $\begin{array}{l}\text { Typical BLR case } \\
\text { (relatively T4) } \\
\text { Deformity of } \\
\text { bronchus were } \\
\text { evident } \\
\text { Finally curative } \\
\text { resection }\end{array}$ \\
\hline \#4 & $\begin{array}{l}\text { c-stage III } \\
\text { cT3N2M0 }\end{array}$ & Middle & $\begin{array}{l}\text { DCF } 2 \text { cycles } \\
\quad+\text { CRT }\end{array}$ & No & pT4b(Br)N2M0 & Grade 1a & $\begin{array}{l}\text { Typical BLR case. } \\
\text { Adhesion area of } \\
\text { trachea is not as } \\
\text { wide as T4 } \\
\text { Finally not curative } \\
\text { resection }\end{array}$ \\
\hline$\# 5$ & $\begin{array}{l}\text { c-stage III } \\
\text { cT3N2M0 }\end{array}$ & Middle & DCF 3 cycles & No & $\mathrm{pT} 4 \mathrm{~b}(\mathrm{Ao}) \mathrm{N} 2 \mathrm{M} 0$ & Grade 1a & $\begin{array}{c}\text { Typical BLR case } \\
\text { (relatively T3). } \\
\text { Adhesion area } \\
\text { was relatively } \\
\text { small to aorta }\end{array}$ \\
\hline
\end{tabular}


targets. The Japan Esophageal Oncology Group (JEOG) compared inter-institutional heterogeneity for locally advanced esophageal cancer. It failed to show any survival differences among the selected institutions [15]. However, precise analyses of IEH in real-world setting for locally advanced ESCC were not conducted. To clarify IEH, we conducted a clinical diagnostic imaging questionnaire study on medical staff (surgeons, medical oncologists, and an imaging radiologist) of BLR cases of ESCC.

\section{Patients and methods}

\section{Study procedure}

The overall study procedure is shown in Fig. 1. Five cases with clinical T3 or T4 (Table 1; Figs. 2, 3, 4, 5, 6) were selected by the primary investigator (Y. H.), who did not answer the questionnaire. The reasons for selection were as follows: case \#1 (Fig. 2): typical T3 case and initially judged as resectable; cases \#2 (Fig. 3) and \#3 (Fig. 4): typical BLR cases that were finally converted to resectable; and cases \#4 (Fig. 5) and \#5 (Fig. 6): typical BLR cases that were finally unresectable cases. All cases were treated with triplet chemotherapy, including DCF. They were evaluated after completion of 2 or 3 cycles of chemotherapy as to whether they were resectable. One case (\#4) received subsequent chemoradiotherapy. All cases underwent attempted esophagectomy, although two cases (\#4 and \#5) could not achieve curative surgery and the final diagnoses were pathological T4b (Bronchus or Aorta). The other three cases (\#1, \#2, and \#3) were finally diagnosed as resectable.

Imaging with esophagoscopy, CT, and esophagography was conducted. Information about patient characteristics and the clinical course was not revealed to the evaluators. Evaluators were selected from members of a weekly oncology board for upper gastrointestinal disease. Twenty-five doctors answered this evaluation study. Information about the evaluators is shown in Table 2. This study was approved by the institutional review board at the Keio University School of Medicine (20160048).
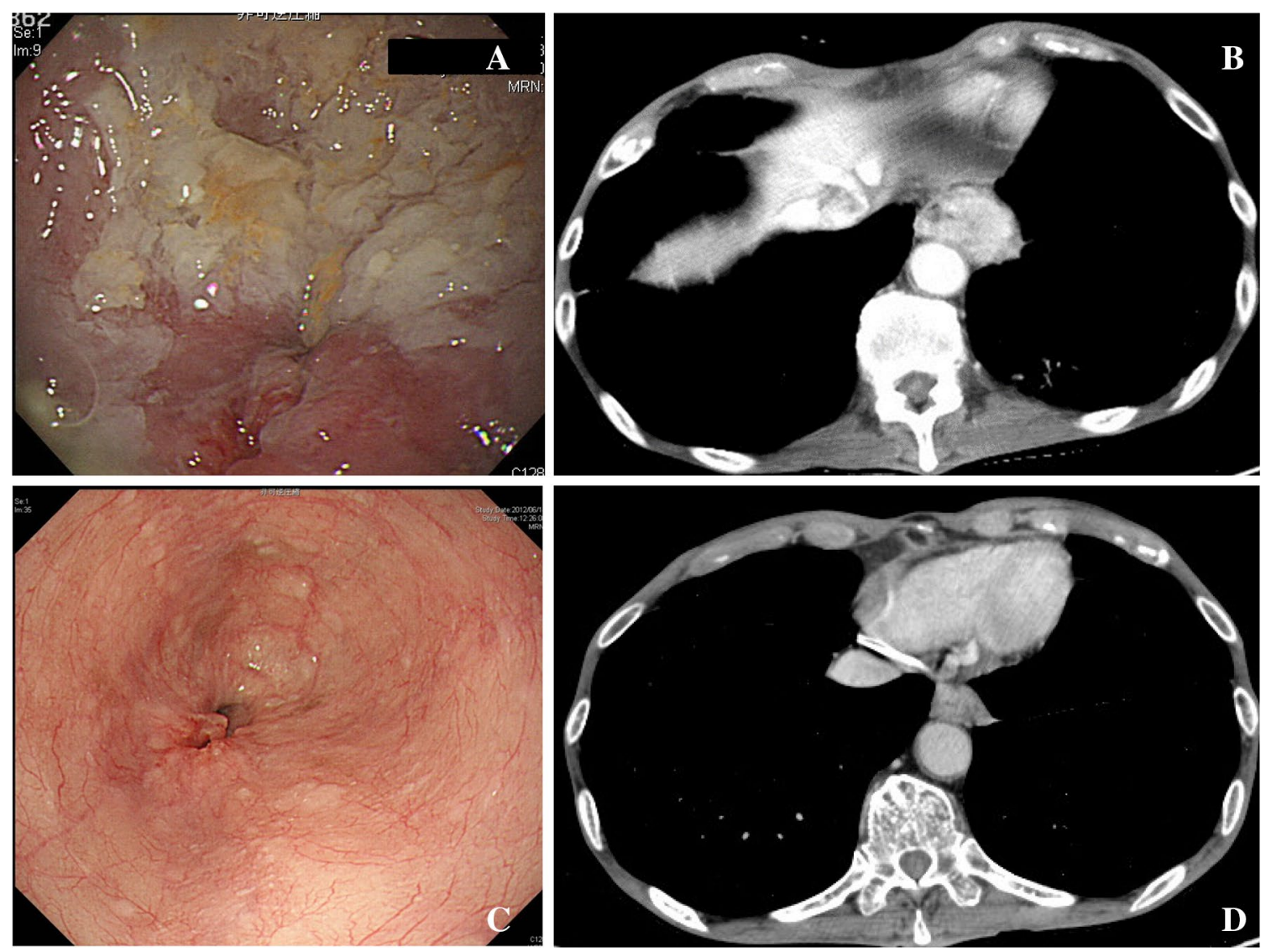

Fig. 2 Case \#1. This case selected as clinical T3 case. Adhesion to aorta or not is important differential diagnosis, although it was not as wide as T4. This case was finally resectable after chemotherapy. a
Endoscopic findings before chemotherapy. b Computer tomography before chemotherapy. c Endoscopic findings after chemotherapy. d Endoscopic findings before chemotherapy 

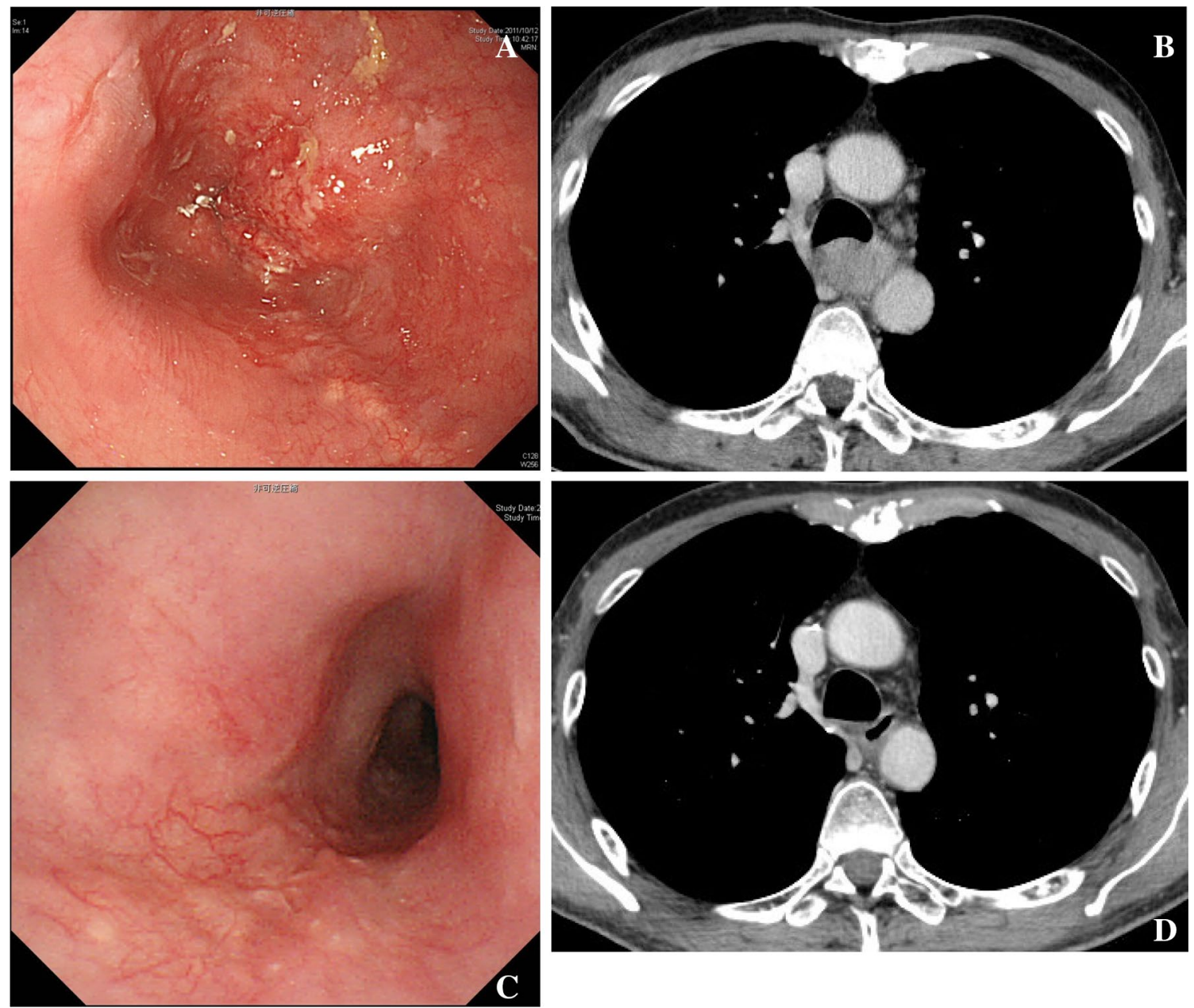

Fig. 3 Case \#2. This case selected as typical BLR case (relatively T4). Deformity of bronchus was evident. This case was finally resectable after chemotherapy. a Endoscopic findings before chemotherapy.

\section{Evaluation}

Each evaluator provided an opinion in an independent manner. The first question was the clinical diagnosis before chemotherapy. The evaluator could select from four answers: definite $\mathrm{T} 4$, suspected $\mathrm{T} 4$, suspected $\mathrm{T} 3$, and definite $\mathrm{T} 3$. The second question was about resectability after chemotherapy. The evaluator could select from three answers: resectable (curative), hard to decide, and unresectable.

\section{Assessment of inter-evaluator heterogeneity}

IEH was assessed by agreement of T3 or T4. Definite T4 and suspected T4 were classified as clinical T4. Suspected T3 and definite T4 were classified as clinical T3. IEH was also compared for occupational differences. The clinical diagnosis of the staff surgeons, non-staff surgeons, and non-surgeon (medical oncologists and b Computer tomography before chemotherapy. c Endoscopic findings after chemotherapy. d Endoscopic findings before chemotherapy

imaging radiologist) was compared. A discrepancy was defined as the clinical T4 converted to resectable.

\section{Results}

\section{General IEH of clinical diagnosis}

Overall results are summarized in Table 3. In case \#1, IEH was observed for clinical diagnosis before chemotherapy (clinical T4: 52\%, clinical T3: 48\%). In cases \#2-\#5, most evaluators diagnosed it as clinical T4 with 76-88\% agreement and no evaluators diagnosed it as definitive T3. IEH for clinical diagnosis of resectability was relatively small. For cases \#1-\#3, more than 70\% of evaluators answered resectable; for cases \#4 and \#5, only 13 and $17 \%$ evaluators answered resectable, respectively. Answers of unknown were increased in cases \#4 and \#5 (54\%). Comparing clinical diagnoses before and 

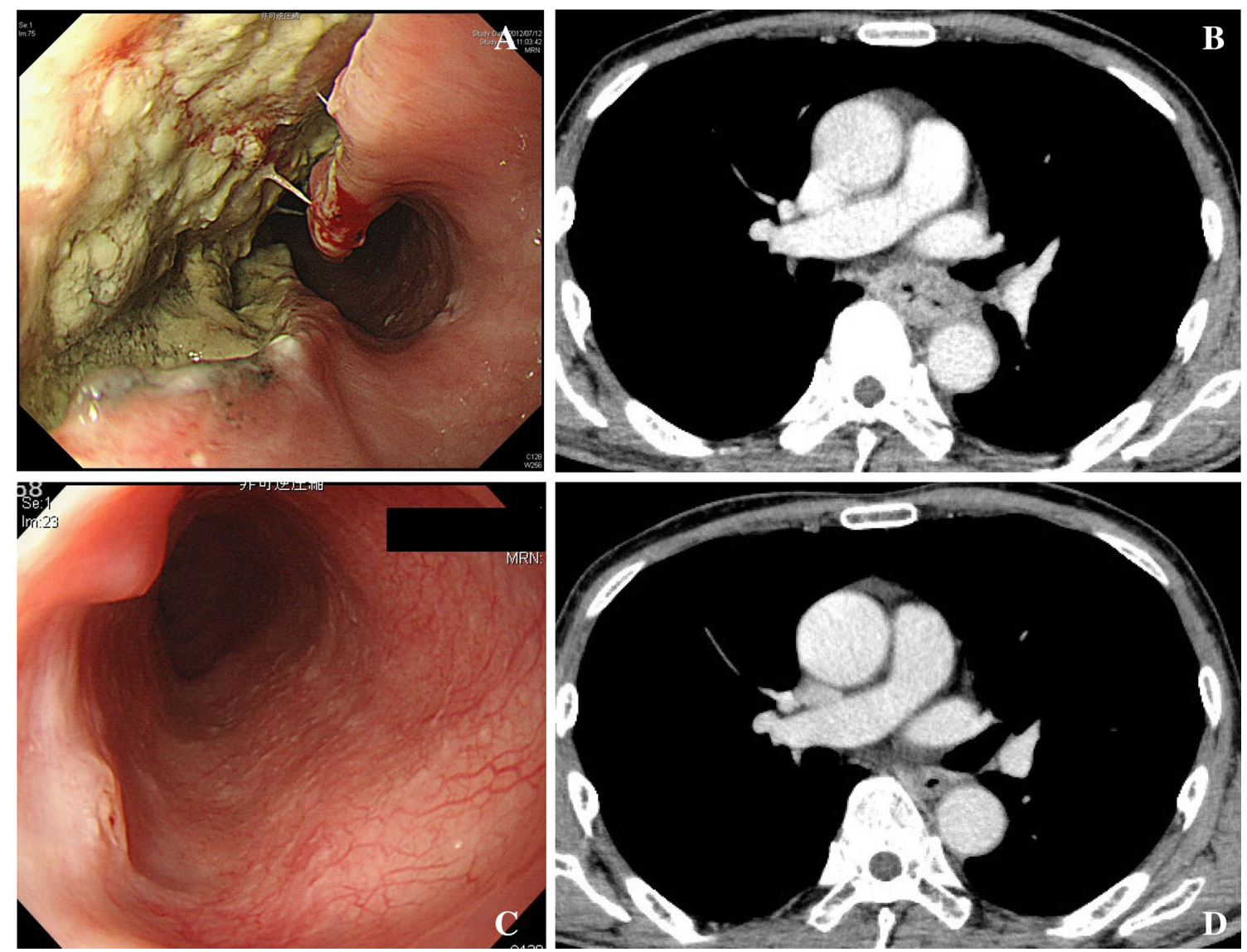

Fig. 4 Case \#3. This case selected as typical BLR case (relatively T4). Deformity of bronchus was evident. This case was finally resectable after chemotherapy. a Endoscopic findings before chemotherapy.

after chemotherapy, cases \#2 and \#3 were converted to resectable after the initial treatment, although the clinical diagnosis from evaluators was $\mathrm{T} 4$ before chemotherapy $(p<0.001)$. Cases \#4 and \#5 were not converted to resectable $(p=1.000$ and 0.250 , respectively).

\section{IEH by occupations}

Occupational differences are shown in Fig. 7. IEH before chemotherapy was also observed. In case \#3, clinical evaluations of $\mathrm{T}$ stage were split (\#3: 50\%) among staff surgeons. Clinical evaluations were also split into cases $\# 1$ and \#5; however, the difference was relatively small (\#1: 33\%, \#5: 67\%). IEH between occupations was observed in case \#1. Most non-staff surgeons evaluated it as $\mathrm{T} 4$, although staff surgeons, medical oncologists, and the imaging radiologist did not evaluate it as T4. IEH for resectability after chemotherapy was observed in case \#2 by medical oncologists. Other heterogeneity was relatively small compared to the evaluation of the imaging radiologist. b Computer tomography before chemotherapy. c Endoscopic findings after chemotherapy. d Endoscopic findings before chemotherapy

\section{Discussion}

In our study, several types of IEH in locally advanced ESCC were observed. Occupational differences were seen even among experienced surgical oncologists. However, most of the differences in clinical judgments were relatively small. The depth of invasion of esophageal cancer needs to consider in the direction of the ulcer. The $\mathrm{CT}$ images need to adjust with information provided by endoscopic findings [16]. This method with combined evaluation of CT and endoscopy for $\mathrm{T} 4$ diagnosis is widely known in matured surgical and medical oncologist for esophageal cancer, however, not familiar in less experienced doctors.

IEH was observed in each occupation. First, non-staff surgeons over-estimated T3 disease (case \#1). Case \#1 was selected as a typical T3, and most staff surgeons, medical oncologists, and the imaging radiologist did not evaluate it as T4. This case was lower thorax cancer with aorta invasion suspected. However, adhesion area was not as wide as definitive T4. This IEH could explain the experimental 


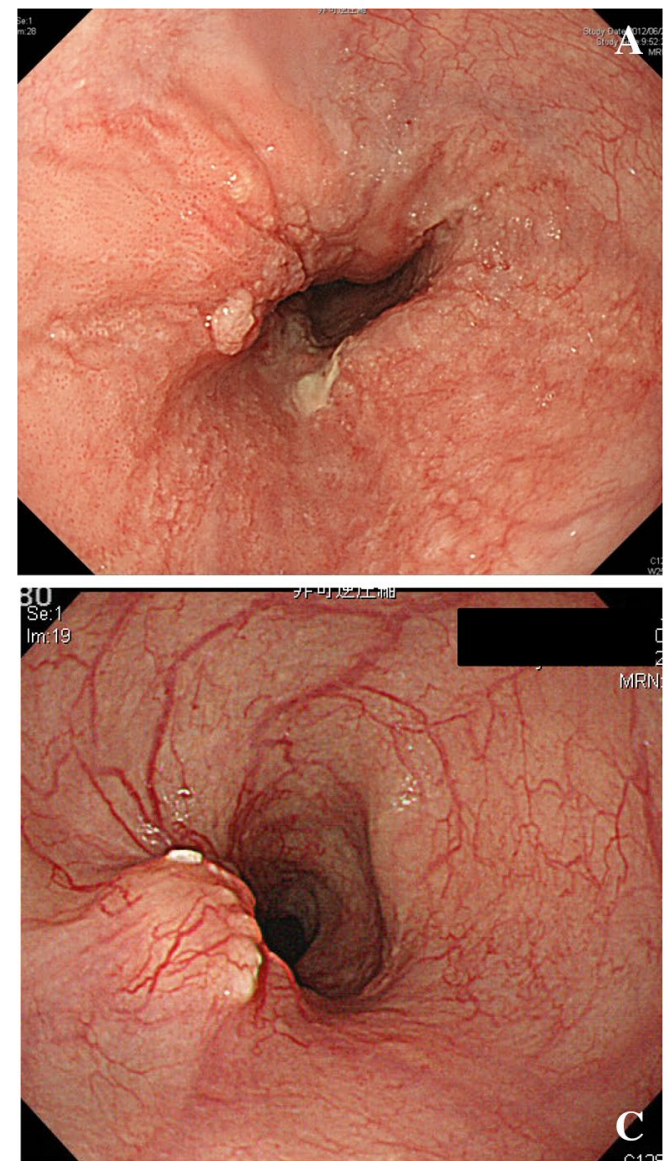

Fig. 5 Case \#4. This case selected as typical BLR case. This case fails to remove completely after chemotherapy. a Endoscopic findings before chemotherapy. b Computer tomography before chemotherapy.

heterogeneity of locally advanced ESCC. This kind of IEH could be expected in law-volume centers for ESCC [17-19]. Second, occupational differences were observed between medical oncologists and other occupations for clinical resectability after chemotherapy. In case $\# 2$, most surgeons, including non-staff, evaluated it as resectable, although most medical oncologists did not consider it resectable. This case was finally resectable, and therefore, judgment of resectability seems established in surgical oncologists. It was also explained that attitude of each professional could affect the judgments. This IEH could also explain the conservative attitude of medical oncologists for converting to surgery. These two IEH could be overcome by educational programs and multi-disciplinary team activity through an oncology board.

Finally, there was IEH among staff surgeons for cases $\# 1$ and \#3. This IEH reflected the fact that the definition of $\mathrm{T}$ stage is not mature. Especially, difference of trachea or aorta invasion is important. In general, T4 diagnosis of trachea/bronchus is rather difficult. Half of the staff surgeon was matured esophageal surgical oncologists; however,

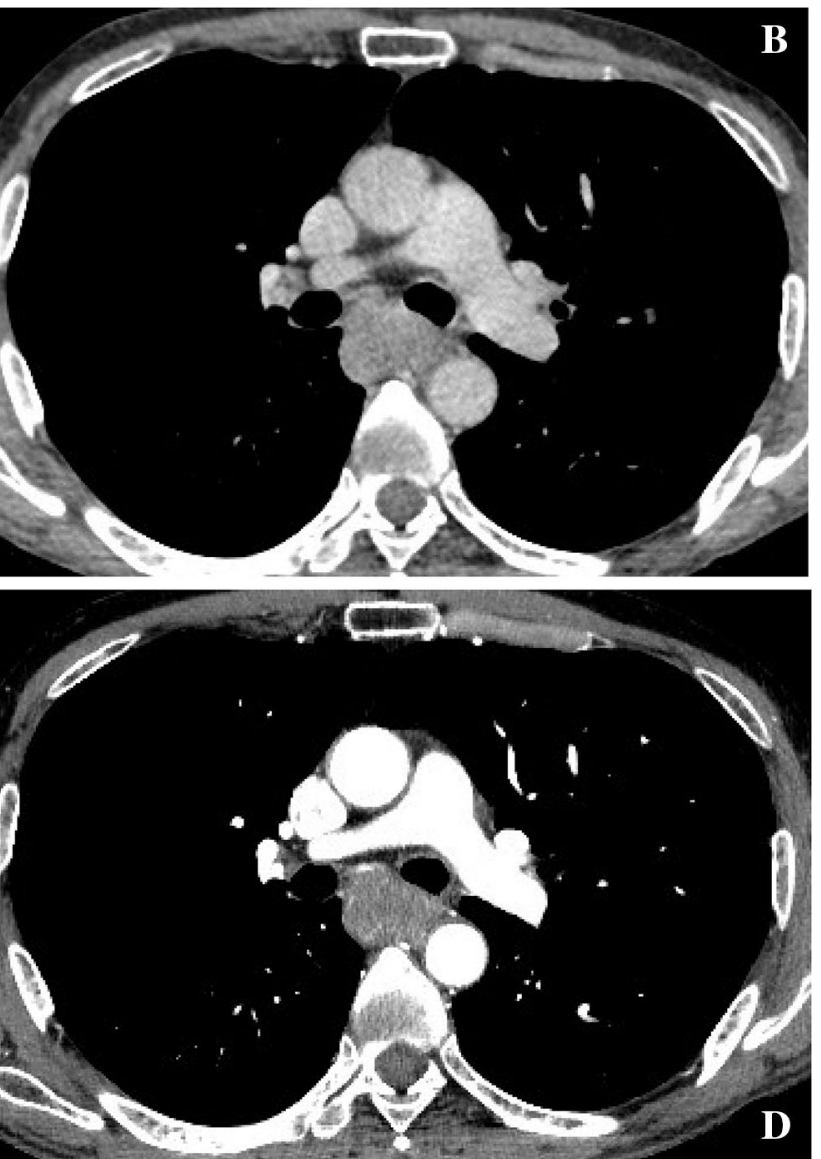

c Endoscopic findings after chemotherapy. d Endoscopic findings before chemotherapy

half of them were upper gastrointestinal surgeon mainly for stomach. To overcome this IEH, education and more experience for esophageal cancer treatments are important solution. However, it may be insufficient. Categorization and clarification of BLR, if possible, is one of good resolution. Another consideration for solving this problem is including BLR cases to T3 or T4 disease in clinical practice. After completion of neo-adjuvant treatment, re-evaluate resectability with multi-disciplinary team. It could also evaluate with clinical trial. After completion of enrollment, pre-planned subgroup analysis with BLR and definitive T4 cases will find some answers. A well-designed clinical trial could have the potential to solve the problem.

Our study clearly shows that clinical diagnoses 'before chemotherapy' were not conclusive; however, IEH 'after chemotherapy' was relatively small and reliable. We have already reported a prospective trial of the triplet regimen for ESCC clinical T4 cases, including BLR [19]. This study investigated the efficacy and safety of an initial DCF regimen followed by selected surgery if possible. As far as we know, this phase 2 trial is the first clinical trial for ESCC 

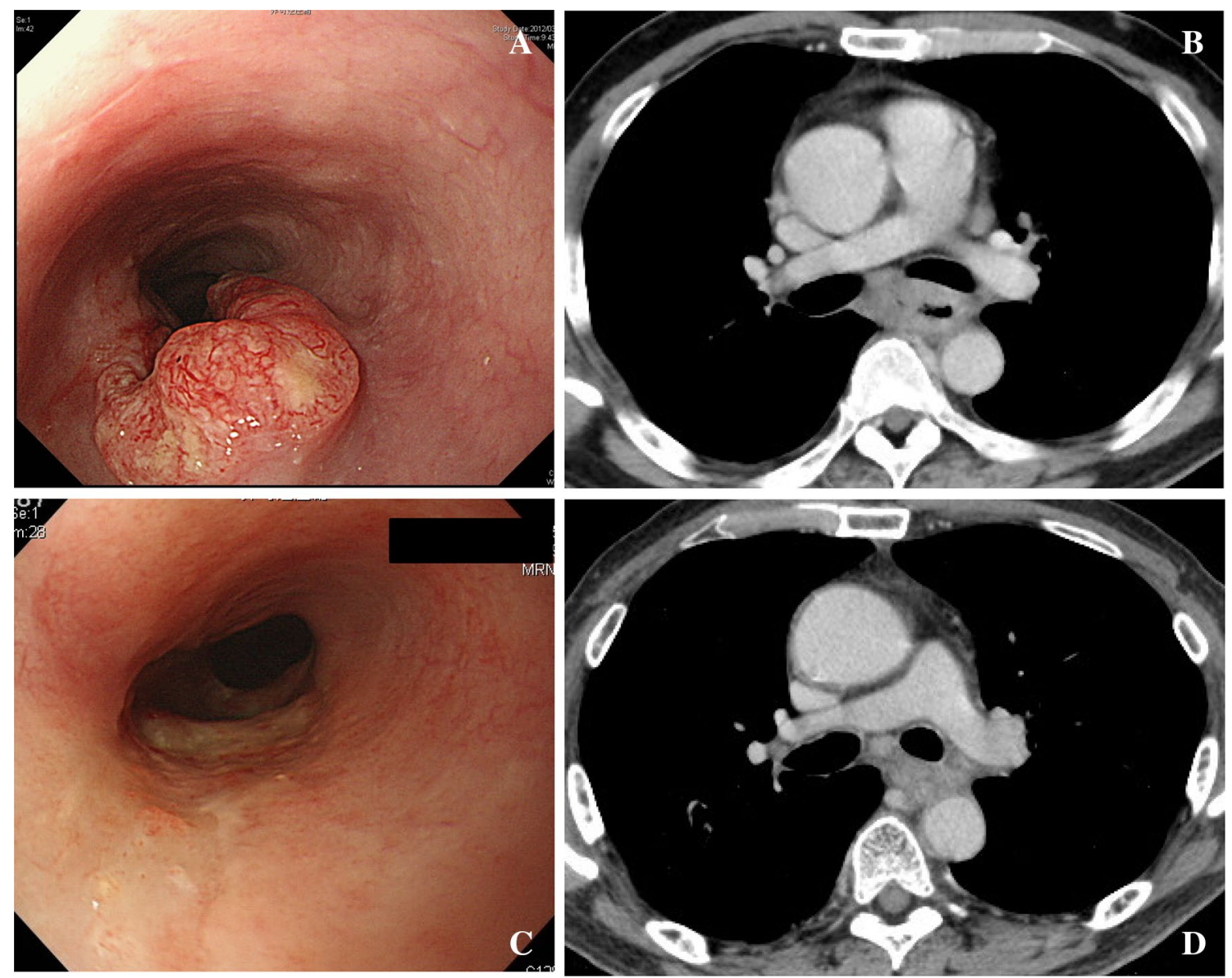

Fig. 6 Case \#5. This case selected as BLR case. Although adhesion area was limited, this case fails to resect completely after chemotherapy. a Endoscopic findings before chemotherapy. b Computer tomog-

Table 2 Characteristics of evaluators

\begin{tabular}{lrl}
\hline Evaluator & N & Career year (mean, median) \\
\hline Surgeon: staff & 6 & $17-27(21.2,20)$ \\
Surgeon: non-staff & 14 & $5-11(6.9,6)$ \\
Medical oncologist & 4 & $6-25(17,18.5)$ \\
Imaging radiologist & 1 & 27 \\
Overall & 25 & $5-27(12.7,8)$ \\
\hline
\end{tabular}

to include BLR disease. We are now planning to conduct a phase 3 trial to evaluate neo-adjuvant DCF treatment for clinical T4 cases, including BLR cases, in JEOG.

Our study has several limitations to consider. First, this study is a single institution analysis and there were imbalances of profession. Non-surgical evaluator, especially imaging radiologist, was alone. We need to consider inter-professional bias in this study. Further raphy before chemotherapy. c Endoscopic findings after chemotherapy. d Endoscopic findings before chemotherapy

Table 3 Summary of the study

\begin{tabular}{|c|c|c|c|c|c|}
\hline \multirow[t]{2}{*}{ Evaluation } & \multicolumn{3}{|c|}{$\begin{array}{l}\text { Finally resected } \\
(\%)\end{array}$} & \multicolumn{2}{|c|}{$\begin{array}{l}\text { Finally not } \\
\text { resected (\%) }\end{array}$} \\
\hline & $\# 1$ & \#2 & \#3 & \#4 & $\# 5$ \\
\hline \multicolumn{6}{|c|}{ Clinical diagnosis (before chemotherapy) } \\
\hline Definite T4 & 20 & 56 & 44 & 32 & 36 \\
\hline Suspect T4 & 32 & 32 & 36 & 56 & 40 \\
\hline $\begin{array}{l}\text { Clinical T4 (definite } \mathrm{T} 4+\text { suspect } \\
\text { T4) }\end{array}$ & 52 & 88 & 80 & 88 & 76 \\
\hline Suspect T3 & 40 & 12 & 20 & 12 & 24 \\
\hline Definite T3 & 8 & 0 & 0 & 0 & 0 \\
\hline $\begin{array}{l}\text { Clinical T3 (suspect T3 + definite } \\
\text { T3) }\end{array}$ & 48 & 12 & 20 & 12 & 24 \\
\hline \multicolumn{6}{|c|}{ Clinical diagnosis of resectability (after chemotherapy) } \\
\hline Resectable (R0) & 76 & 76 & 72 & 8 & 12 \\
\hline Hard to decide & 20 & 12 & 20 & 28 & 28 \\
\hline Unresectable & 4 & 12 & 8 & 64 & 60 \\
\hline
\end{tabular}


Fig. 7 a Inter-evaluator heterogeneity of clinical $\mathrm{T}$ diagnosis. b Inter-evaluator heterogeneity of clinical judgment for resectability

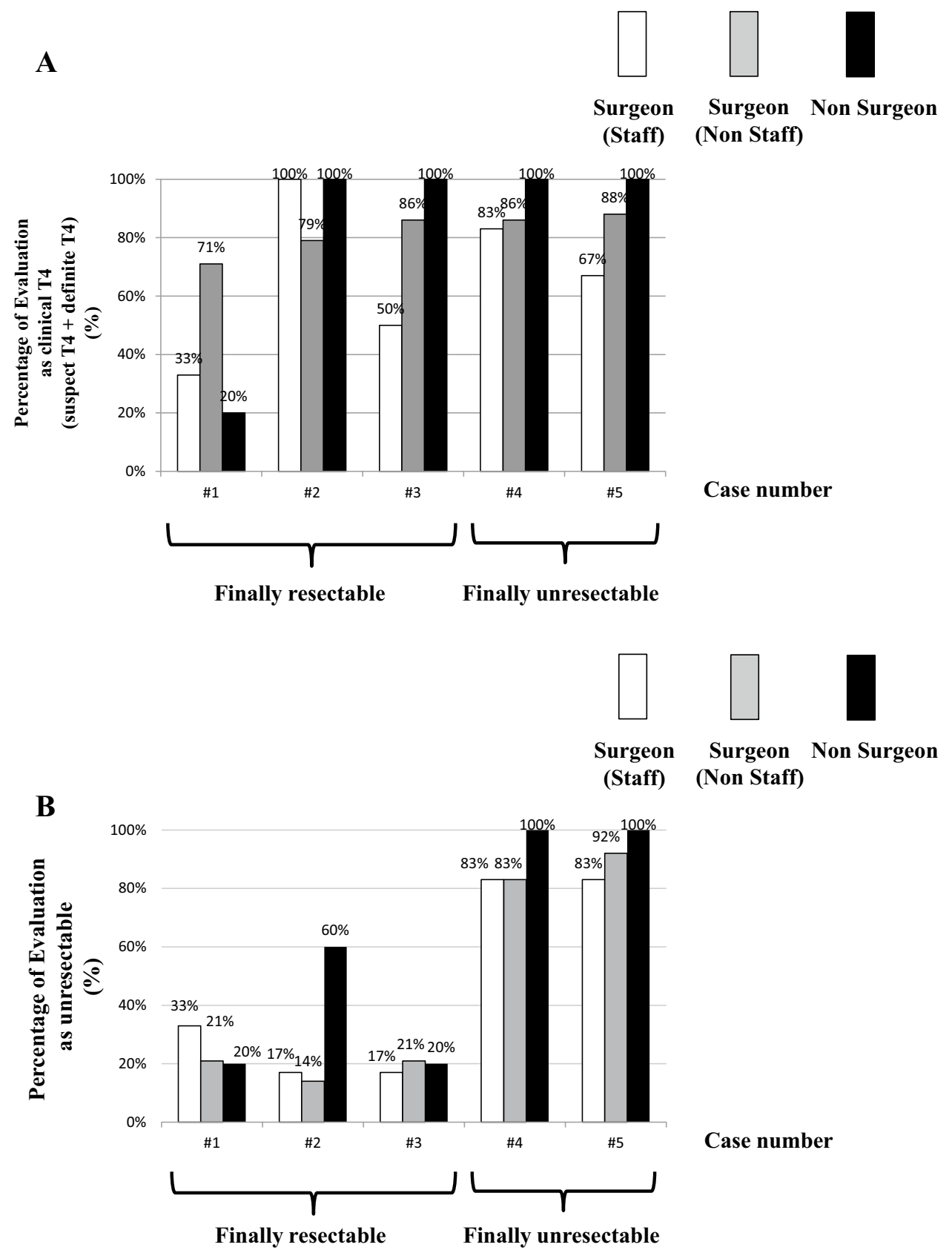

confirmative study or other method is needed to clarify this bias. Second, the number of evaluated cases was small; only five cases were chosen from a single institution. In addition, we need to consider memory bias. Third, the case selection by investigator had a potential bias. Finally, it is possible that these questionnaires itself mislead the evaluators' answers. It is also important educational aspect of questionnaires during question through case \#1 to case \#5.

In conclusion, IEH of evaluating BLR cases in ESCC needs to be considered. A multi-disciplinary team is essential to overcome this problem. 
Acknowledgements We thank the members of the weekly oncology board upper gastrointestinal meeting who participated in this study.

\section{Compliance with ethical standards}

Ethical Statement Authors declare that our work conforms to the guidelines set forth in the Helsinki Declaration of 1975, as revised in 2000 (5), concerning Human and Animal Rights, and that they followed the policy concerning Informed Consent.

Conflict of interest Yuko Kitagawa has conflicts of interest to declare with regard to this manuscript: Ethicon, Ono Pharmaceutical co., Taiho Pharma, Chugai Pharmaceutical co., Asahi Kasei Pharma, Otsuka Pharmaceutical Co., Kyowa Hakko Kirin Co., Daiichi Sankyo Co., Takeda Pharmaceutical Co. Nippon Boehringer Ingelheim Co., Novartis Pharma., Pfeizer Japan, Merck Serono Co., Yakult Honsha Co., Terumo Corporation, Torii Pharmaceutical Co., Astra Zeneca. Yasuo Hamamoto has conflicts of interest to declare with regard to this manuscript: Chughai-pharm. Ono Pharmaceutical co., Taiho Pharma., Yakult honsha.

Funding This work was supported by the Japan Society for the Promotion of Science (JSPS) Grant-in-Aid for Scientific Research (Grant No. 16K08880).

Open Access This article is distributed under the terms of the Creative Commons Attribution 4.0 International License (http://creativecommons.org/licenses/by/4.0/), which permits unrestricted use, distribution, and reproduction in any medium, provided you give appropriate credit to the original author(s) and the source, provide a link to the Creative Commons license, and indicate if changes were made.

\section{References}

1. Rustgi AK, El-Serag HB. Esophageal Carcinoma. N Engl J Med. 2014;371:2499-509.

2. Ohtsu A, Boku N, Muro K, et al. Definitive chemoradiotherapy for T4 and/or M1 lymph node squamous cell carcinoma of the esophagus. J Clin Oncol. 1999;17:2915-21.

3. Nishimura Y, Hiraoka M, Koike R, et al. Long-term follow-up of a randomized Phase II study of cisplatin/5-FU concurrent chemoradiotherapy for esophageal cancer (KROSG0101/JROSG021). Jpn J Clin Oncol. 2012;42(9):807-12.

4. Shinoda M, Ando N, Kato K, Japan Clinical Oncology Group, et al. Randomized study of low-dose versus standard-dose chemoradiotherapy for unresectable esophageal squamous cell carcinoma (JCOG0303). Cancer Sci. 2015;106(4):407-12.

5. Akutsu Y, Matsubara H. Chemoradiotherapy and surgery for T4 esophageal cancer in Japan. Surg Today. 2015;45(11):1360-5. doi:10.1007/s00595-015-1116-4 (Epub 2015 Jan 13).
6. Stahl M, Stuschke M, Lehmann N, et al. Chemoradiation with and without surgery in patients with locally advanced squamous cell carcinoma of the esophagus. J Clin Oncol. 2005;23:2310-7.

7. Bedenne L, Michel P, Bouché $\mathrm{O}$, et al. Chemoradiation followed by surgery compared with chemoradiation alone in squamous cancer of the esophagus: FFCD 9102. J Clin Oncol. 2007;25(10):1160-8.

8. Matsubara T, Ueda M, Kokudo N, et al. Role of esophagectomy in treatment of esophageal carcinoma with clinical evidence of adjacent organ invasion. World J Surg. 2001;25:279-84.

9. Ikeda K, Ishida K, Sato N, et al. Chemoradiotherapy followed by surgery for thoracic esophageal cancer potentially or actually involving adjacent organs. Dis Esophagus. 2001;14:197-201.

10. Fujita H, Sueyoshi S, Tanaka T, et al. Esophagectomy; is it necessary after chemoradiotherapy for a locally advanced $\mathrm{T} 4$ esophageal cancer? Prospective nonrandomized trial comparing chemoradiotherapy with surgery versus without surgery. World J Surg. 2005;29:25-30.

11. Yokota T, Hatooka S, Ura T, et al. Docetaxel plus 5-fluorouracil and cisplatin (DCF) induction chemotherapy for locally advanced borderline-resectable T4 esophageal cancer. Anticancer Res. 2011;31(10):3535-41.

12. Hamamoto Yasuo, Onodera Kei, Saito Mayuko, et al. Case series of preoperative triplet-regimen (docetaxel, CDDP and 5-fluorouracil) for borderline resectable T4 thoracic esophageal carcinoma. Esophagus. 2013;10(4):205-10.

13. Miyata H, Yamasaki M, Kurokawa Y, et al. Clinical relevance of induction triplet chemotherapy for esophageal cancer invading adjacent organs. J Surg Oncol. 2012;106(4):441-7.

14. Picus D, Balfe D, Koehler R, et al. Computed tomography in the staging of esophageal carcinoma. Radiology. 1983;146:433-8.

15. Yamabe $Y$, Kuroki $Y$, Ishikawa $T$, et al. Tumor staging of advanced esophageal cancer: combination of double-contrast esophagography and contrast-enhanced CT. Am J Roentgenol. 2008;191(3):753-7.

16. Hamamoto Y, Mizusawa J, Katayama H, et al. Inter-institutional survival heterogeneity in chemoradiation therapy for esophageal cancer: exploratory analysis of the JCOG0303 study. Jpn J Clin Oncol. 2016;46(4):389-92.

17. Kuwano H, Nishimura Y, Oyama T, et al. A guidelines for diagnosis and treatment of carcinoma of the esophagus April 2012 edited by the Japan Esophageal Society. Esophagus. 2015;12:1-30.

18. Wouters MW, Gooiker GA, van Sandick JW, et al. The volume-outcome relation in the surgical treatment of esophageal cancer: a systematic review and meta-analysis. Cancer. 2012;118:1754-63.

19. Yokota T, Kato K, Hamamoto Y, et al. Phase II study of chemoselection with docetaxel plus cisplatin and 5-fluorouracil induction chemotherapy and subsequent conversion surgery for locally advanced unresectable oesophageal cancer. Br J Cancer. 2016;115(11):1328-34. 